conventional DMARD-experienced ABA- and TOF-treated pts. Treatment-related death was not analysed in an NMA due to insufficient data.

Results: Thirty-one randomised controlled trials $(n=13,978)$ were included for data extraction. Of these, $\mathrm{ABA}$ and TOF were examined in 16 and 15 trials, respectively. There were no head-to-head comparisons of ABA vs TOF. Most of the trial population were Caucasian (48\%-98\% across trials), had an average age ranging from 40 to 60 years and were predominantly female $(60 \%-90 \%)$. Of the trials, 26 included a US population and 5 a non-US population. Out of 11 studies reporting treatment-related mortality, one study reported four deaths for pts on TOF $5 \mathrm{mg}(\mathrm{n}=321)$ within a 1 year follow-up. No such deaths were reported for ABA pts. The NMAs showed no significant differences in the risk of TrAEs for pts on TOF 5 or $10 \mathrm{mg}$ compared with ABA with/without MTX (TOF $5 \mathrm{mg}+\mathrm{MTX}$ vs $\mathrm{ABA}+\mathrm{MTX}$ : risk ratio [RR] 1.1, 95\% $\mathrm{Cl}: 0.77,1.5$; TOF $10 \mathrm{mg}$ vs ABA: RR 1.1, $95 \% \mathrm{Cl}: 0.78,1.6)$. These findings remained consistent for the risk of total AEs and serious infections.

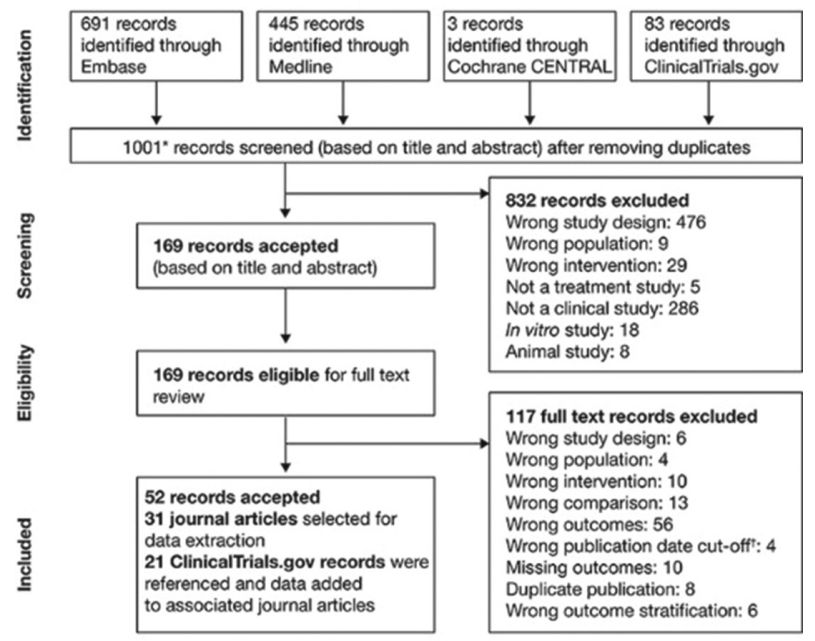

Abstract AB0427 - Figure 1. PRISMA Diagram Showing Study Selection

*One reference identified manually from a ClinicalTrials.gov record

Wrong publication date cut-off: meeting abstract published before 2015

Conclusions: Without head-to-head trials, the data available to make comparisons between abatacept and TOF are limited. Even after conducting an SLR and NMAs, precision is lacking in estimating differences. Additional studies, such as real-world observational analyses with larger patient samples and higher incidence of measured outcomes, are needed to further examine the safety differences of abatacept vs TOF

Disclosure of Interest: D. Paul Employee of: Bristol-Myers Squibb, R. Diekemper Grant/research support from: Bristol-Myers Squibb, Employee of: Doctor Evidence, M. Fazeli Grant/research support from: Bristol-Myers Squibb, Employee of: Doctor Evidence, F. Husain Grant/research support from: Bristol-Myers Squibb, Employee of: Doctor Evidence, A. Marshall Shareholder of: Bristol-Myers Squibb, Employee of: Bristol-Myers Squibb, Y. Kuang Grant/research support from: Bristol-Myers Squibb, Employee of: Doctor Evidence, T. Curtice Employee of: Bristol-Myers Squibb

DOI: 10.1136/annrheumdis-2018-eular.2609

\section{AB0428 2 PREFERENCES IN THE USE OF BIOLOGIC DRUGS AND ADVERSE EVENTS IN PATIENTS WITH RHEUMATIC DISEASE FROM A NATIONAL BIOLOGICS REGISTRY IN MÉXICO}

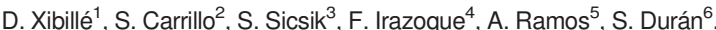

M. Saavedra ${ }^{7}$, L. Barile ${ }^{8}$, G. Olvera ${ }^{8} .{ }^{1}$ SSM, Cuernavaca; ${ }^{2}$ Hospital 1 Oct, ISSSTE, México; ${ }^{3}$ UMAE 71 IMSS, Torreón; ${ }^{4}$ CMN 20 Nov, ISSSTE, México; ${ }^{5}$ CMN NE 25 IMSS, Monterrey; ${ }^{6}$ CIRO SC, Guadalajara; ${ }^{7} \mathrm{HE}$ CMN La Raza, IMSS; ${ }^{8}$ Colegio Mexicano de Reumatología, México, Mexico

Background: National registries of biologic drugs have proven to be valuable tools in following patients with rheumatic disease and some outcomes in real-life situations.

Objectives: The objective of this study was to describe Mexican Rheumatologists' preferences when treating patients with biologic drugs and to analyse factors associated to the use of this therapy.

Methods: Data from patients undergoing biologic treatment in México is gathered into the BIOBADAMEX online database, which is part of the BIOBADAMERICA initiative and based on the BIOBADASER Phase 3 platform. Phase 3 in México started gathering patient data in April 2016 and to date has information on 216 patients. The database collects information such as gender, age, diagnosis, disease duration, biologic treatment, DMARD treatment, concomitant therapy, motives for discontinuation of biologics, comorbidities, adverse event (AE) severity, infection site and germ involved. Descriptive statistics were applied on the data collected from April 2016 to January 2018.

Results: We analysed data on the use of 267 biologic treatments in 216 patients. Most of them receive biologic therapy through socialised medical insurance programs which may have led to bias. $89.1 \%$ of patients were female, mean age 49 \pm 15.2 (4-85) years, $42.5 \%$ belonging to the $<50$ group. $69.9 \%$ of patients in the registry have RA, $12.5 \%$ AS and $5.5 \%$ PsA. Mean disease duration is $11 \pm 8.9(0$ 58) years. The most commonly used biologic overall is Abatacept (15.3\%), followed by Adalimumab (13.8\%), Tocilizumab (11.2\%), Certolizumab (10.1\%), Golimumab (8.6\%), Rituximab (8.2\%), Etanercept biosimilar (7.4\%), Etanercep $(6.3 \%)$, Infliximab (4.1\%) and Benlystia (1.1\%). All others, including JAK inhibitors, are used in $<1 \%$ of patients. The preference for first biologic drug was Etanercept (32.4\%), followed by Adalimumab (12\%), Infliximab (8.3\%), Rituximab and Tocilizumab (5.5\% each) and Abatacept (2.7\%). Most treatments were stopped due to lack of efficacy $(60.4 \%)$, disease remission $(7.4 \%)$, other causes $(20.1 \%), A E$ $(4.4 \%)$, with the rest of the causes each affecting $<5 \%$ of patients. The most com monly used DMARD were Methotrexate (49.8\%), steroids (33.3\%) and leflunomide $(23.2 \%)$. Comorbidities were present in 87 patients $(40 \%)$, the most common being Hypertension (13.4\%), Diabetes (7.8\%) and Dyslipidemia (6.9\%) Non-lymphoma neoplasms were reported in $1.3 \%$. $25 \%$ of $A E$ were considered serious but most $(70 \%)$ were mild. Only 6 patients reported infections with the most common sites being the skin $(33.3 \%)$, urinary tract $(16.6 \%)$ and middle-ear (16.6\%). The causal germ was often undetermined (60\%).

Conclusions: When using biologic drugs, TNF inhibitors are the most commonly used initial mechanism of action for the treatment of rheumatic diseases in the BIOBADAMEX registry. Upon treatment failure, patients undergo a switch to another mechanism of action, mainly using Abatacept. Adverse events and infections related to the use of biologics are infrequent, but $40 \%$ of patients present chronic comorbidities

Disclosure of Interest: D. Xibillé Speakers bureau: Abbvie, Pfizer, BMS, S. Carrillo Speakers bureau: Abbvie, Pfizer, BMS, Roche, S. Sicsik Speakers bureau: Roche, Pfizer, BMS, F. Irazoque Speakers bureau: Abbvie, Pfizer, BMS, Roche A. Ramos: None declared, S. Durán: None declared, M. Saavedra: None declared, L. Barile Speakers bureau: Abbvie, Pfizer, BMS, Roche, G. Olvera: None declared

DOI: 10.1136/annrheumdis-2018-eular.4832

\section{AB0429 NO DIFFERENCE IN EFFECTIVENESS WITH EITHER ETANERCEPT ORIGINATOR OR BIOSIMILAR AS FIRST LINE BIOLOGIC TREATMENT FOR RHEUMATOID ARTHRITIS}

D. De Cock $^{1}$, R. Davies ${ }^{1}$, L. Kearsley-Fleet ${ }^{1}, K$. Watson ${ }^{1}, K$. Hyrich ${ }^{1,2}$, on behalf of the BSRBR-RA contributor group. ${ }^{1}$ Arthritis Research UK Centre for Epidemiology, Manchester University, ${ }^{2}$ Manchester Academic Health Science Centre, Central Manchester NHS Foundation Trust, Manchester, UK

Background: Biosimilars and their reference agents have been shown to be equivalent in clinical trials. In the United Kingdom, etanercept biosimilars (ETA-B) are, since 2016, a first-line treatment option for the management of severe rheumatoid arthritis (RA) defined as no response to 2 or more csDMARDs. However, real world data, including how it compares to the etanercept originator (ETA-O) are lacking.

Objectives: This study aims to compare the short-term effectiveness of etanercept originator with its biosimilar in patients with RA when used as a first biologic following csDMARDs.

Methods: This study included patients with RA registered with the British Society for Rheumatology Biologics Registers for RA (BSRBR-RA) at the point of starting either ETA-O or an ETA-B since 2011 as their first biologic. Baseline information is collected at drug start and includes demographic and clinical data. Follow-up (FU) data are captured every 6 months and include details on therapy changes, current disease activity, and development of any adverse events. The primary outcome of this study is effectiveness as calculated by change in the 28 joint count disease activity score (DAS28). Only patients with a complete DAS28 at baseline and their 1st FU were included in the final analysis of this study. Hazard ratios $(\mathrm{HR})$ comparing drug survival and risk of first serious adverse event (SAE) between ETA-O and ETA-B patients were calculated using Cox regression.

Results: Between January 2010 and 11 December 2017, 1217 and 412 patients starting ETA-O or ETA-B respectively were recruited and had $\geq 1 \mathrm{FU}$ available. Complete DAS28 data at baseline and 1st FU were available for 740 ETA-O patients and 177 ETA-B patients. Patient characteristics were similar between the 2 cohorts (Table). After adjusting for baseline differences, no difference between groups was seen in DAS28 $(p=0.1)$ or remission status $(p=0.1)$ at 1 st FU. 
Nine $(5 \%)$ and $48(6 \%)$ of ETA-B and ETA-O patients had stopped their respective treatments by the 1st FU. The adjusted hazard ratio for stopping ETA-O versus ETA-B over this time period was similar $(H R=0.8(0.4-1.6) ; p=0.5)$. Risk of SAEs over the first 6 months was also similar between groups (HR (ETA-B versus ETAO) $=0.6(0.3-1.1) ; p=0.1)$, with $10(6 \%)$ and $73(10 \%)$ SAEs reported in ETA-B and ETA-O patients respectively until 1 st FU.

Abstract AB0429 - Table 1

\begin{tabular}{|c|c|c|c|}
\hline Patients who are & Biological naive & \begin{tabular}{|l|} 
Switched from a \\
non-originator
\end{tabular} & $\begin{array}{l}\begin{array}{l}\text { Switched from } \\
\text { originator }\end{array} \\
\end{array}$ \\
\hline Number & 36 & 17 & 5 \\
\hline \multicolumn{4}{|l|}{ Biosimilar } \\
\hline Infliximab biosimilars & $28(77 \%)$ & $17(100 \%)$ & $3(60 \%)$ \\
\hline etanercept biosimilar & $8(22 \%)$ & $0(0 \%)$ & $2(40 \%)$ \\
\hline \multicolumn{4}{|c|}{\begin{tabular}{|l|l|} 
ILAR class & \\
\end{tabular}} \\
\hline Persistent Oligoarthritis & $4(11 \%)$ & $4(24 \%)$ & $0(0 \%)$ \\
\hline Extended Oligoarthritis & $8(22 \%)$ & $5(29 \%)$ & $1(20 \%)$ \\
\hline RF Negative Polyarthritis & $13(36 \%)$ & $4(24 \%)$ & $1(20 \%)$ \\
\hline RF Positive Polyarthritis & $0(0 \%)$ & $0(0 \%)$ & $0(0 \%)$ \\
\hline Psoriatic Arthritis & $2(6 \%)$ & $3(18 \%)$ & $3(60 \%)$ \\
\hline Enthesitis Related Arthritis & $8(22 \%)$ & $1(6 \%)$ & $0(0 \%)$ \\
\hline Unknown & $1(3 \%)$ & $0(0 \%)$ & $0(0 \%)$ \\
\hline Active uveitis at start of therapy & $4(11 \%)$ & $7(41 \%)$ & $2(40 \%)$ \\
\hline Female & $22(61 \%)$ & $12(71 \%)$ & $2(40 \%)$ \\
\hline Age (years) & $13(9-15)$ & $14(11-15)$ & $13(12-16)$ \\
\hline Disease duration (years) & $2(1-5)$ & $6(3-10)$ & $7(6-13)$ \\
\hline Active Joints (71 joints) & $2(1-4)$ & $0(0-2)$ & $0(0-0)$ \\
\hline Limited Joints (71 joints) & $2(1-4)$ & $2(0-4)$ & $0(0-1)$ \\
\hline Physician Global $(0-10 \mathrm{~cm})$ & $2(2-4)$ & $1(0-2)$ & $0(0-0)$ \\
\hline Patient Global $(0-10 \mathrm{~cm})$ & $5(1-7)$ & $2(0-4)$ & $2(0-4)$ \\
\hline Pain VAS $(0-10 \mathrm{~cm})$ & $4(1-7)$ & $4(2-5)$ & $1(0-1)$ \\
\hline CHAQ (0-3) & $1(0-1)$ & $0(0-2)$ & $0(0-1)$ \\
\hline
\end{tabular}

Conclusions: In the UK, etanercept biosimilars are now frequently used as firstline biologics in RA patients. These short-term follow-up data demonstrate in routine clinical care that ETA-B appears to be equivalent to ETA-O in terms of short term effectiveness, drug survival and safety.

Disclosure of Interest: None declared

DOI: 10.1136/annrheumdis-2018-eular.4508

\section{AB0430 SUBJECTIVE ASSESSMENTS OF PATIENTS WITH RHEUMATOID ARTHRITISREPORTED THAT BIO- HOLIDAY THERAPY BROUGHT THEM FINANCIAL AND PSYCHOLOGICAL IMPROVEMENTS}

E. Torikai ${ }^{1}$, D. Suzuki ${ }^{1}$, M. Suzuki ${ }^{2}$, Y. Matsuyama ${ }^{2} .{ }^{1}$ Department of Rheumatology, Iwata city hospital, Iwata; ${ }^{2}$ Department of Orthopaedic surgery, Hamamtsu university school of medicine, Hamamatsu, Japan

Background: At EULAR 2016 and 2017 we reported that it is possible to maintain disease activity, radiographic progression, physical function, and bone metabolism status in rheumatoid arthritis (RA) patients with clinical disease activity index (CDAI) remission using the biologic agents (Bio)-holiday therapy. Currently, in RA therapy, subjective assessment of patients as well as objective assessment of doctors is becoming more important ${ }^{(1)}$. How does the patient think about Bio-holiday therapy?

Objectives: We conducted questionnaire survey in RA patients with CDAI remission who underwent Bio-holiday therapy or Bio-continue therapy to evaluate the benefits of their therapies and to clarify the number of patients concerned about flare-up.

Methods: The first and second survey comprised 9 and 11 questions, respectively; each provided predefined answers. In the first survey, we questioned 85 RA patients in CDAl remission: those treated with any DMARDs. We asked them about the expected elements of RA treatment. In the second survey, we questioned two groups of patients with CDAI remission; those treated with Bio-continue after achieved CDAl remission (BC group: $n=26$ ) and those treated with Bio-holiday therapy after achieved CDAl remission (BH group: $n=28)$. We asked them by a questionnaire what was expected from the treatment effect and how much they felt anxiety about the activity of daily life (ADL) deterioration, RA flare-up and treatment costs.

For Bio-holiday therapy, patients with CDAI remission were treated with golimumab or tocilizumab. Bio was discontinued if they achieved CDAI remission. Patients were treated with Bio within 3 months after falling out of CDAl remission. They could be taken off Bio again when they reached CDAl remission.

Results: In the first survey (figure 1), pain improvement and inexpensive treatment were the most and the second expected treatment effect, respectively. In the second survey (Figure 2), for questions regarding expectation from RA treatment effect, the patients reported that the most beneficial points was pain improvement and the second one was the active daily living without difficulty. Patients in both groups equally recognised reduction in pain and recovery of activities of daily living, which are important for patients with CDAI remission. Interestingly, improvement of emotional depression is the higher in $\mathrm{BH}$ group than in $\mathrm{BC}$ group. For question regarding anxiety, the high medical expense was the most anxious point. Anxiety regarding high medical expenses in $\mathrm{BH}$ group was lower than that in $\mathrm{BC}$ group. Anxiety regarding flare-up was equal to that in $\mathrm{BC}$ group as patients were assured of retreatment with Bio in case of a flare-up.

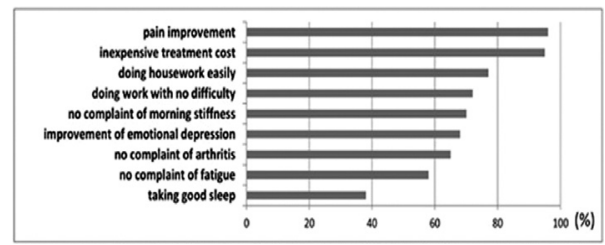

Abstract AB0430 - Figure 1. Questionnaire results of all RA patients with CDAl remission

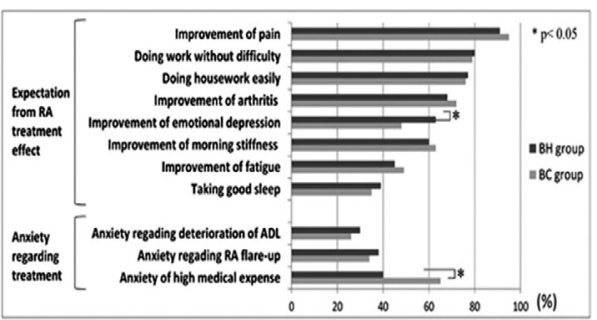

Abstract AB0430 - Figure 2. Questionnaire results of RA patients with CDAI remission who underwent Bio-holiday therapy or Bio-continue therapy

Conclusions: Patients in both groups were equally satisfied with the improvement of their disease activity and progression of ADL. Reduction of the anxiety regarding treatment costs and flare-up in Bio-holiday therapy also helped to improve psychological aspects. Therefore, we recommended Bio-holiday therapy for RA patients with CDAI remission.

\section{REFERENCE:}

[1] Vibeke Strand, et al. J Rheumatol 2015.

Disclosure of Interest: None declared

DOI: 10.1136/annrheumdis-2018-eular.4411

\section{AB0431 EARLIER AGE AT THERAPY INITIATION IS ASSOCIATED WITH BETTER RESPONSE TO TOCILIZUMAB THERAPY IN PATIENTS WITH JUVENILE IDIOPATHIC POLYARTHRITIS}

E. Alexeeva ${ }^{1,2}$, T. Dvoryakovskaya ${ }^{1,2}$, M. Soloshenko $^{1}$, R. Denisova ${ }^{1}, \mathrm{~K}$. Isaeva ${ }^{1}$, A. Mamutova ${ }^{1}$, V. Gladkikh ${ }^{3,4}$, A. Moskalev ${ }^{3,4}$. ${ }^{1}$ National Medical Research Center for Children's Health; ${ }^{2}$ Sechenov First Moscow State Medical University (Sechenov University), Moscow, ${ }^{3}$ EOL Labs Itd, Department of Biostatistics; ${ }^{4}$ Institute of Computational Mathematics and Mathematical Geophysics SB RAS, Novosibirsk, Russian Federation

Background: The use of therapy with anti-cytokine biologicals in routine practice has significantly increased the percentage of children showing good response to therapy and reduced the time to achieve pharmacological remission. Nevertheless, the problem related to selecting the optimal drug for a certain patient still remains to be solved.

Objectives: This study was aimed at identifying clinical and laboratory parameters associated with response to tocilizumab (TOC) treatment in patients with RFnegative polyarticular JIA.

Methods: The prospective study to assess TOC efficacy involved 55 patients with RF-negative polyarticular JIA aged 9.42 years (IQR 5.96-13.42), with females (85.5\%) predominating was conducted at the National Medical Research Centre of Children's Health (Moscow). Treatment efficacy was evaluated using the ACRPedi criteria; Wallace's criteria were used to assess whether a patient had reached inactive disease or remission. The potential baseline characteristics associated with treatment response were identified using univariate and multivariate logistic regression analyses. Baseline factors included the clinical, laboratory and anamnestic data. 